\title{
COMPARISON OF COMMERCIAL STRUCTURE-FROM-MOTION PHOTOGRAMMETY SOFTWARE USED FOR UNDERWATER THREE-DIMENSIONAL MODELING OF CORAL REEF ENVIRONMENTS
}

\author{
J. H. R. Burns ${ }^{a^{*}}$ and D. Delparte ${ }^{b}$ \\ a Hawai'i Institute of Marine Biology, University of Hawai'i at Mānoa, PO Box 1346, Kaneohe, HI 96722, USA - \\ johnhr@hawaii.edu \\ ${ }^{\mathrm{b}}$ Department of Geosciences, Idaho State University, 921 S. 8th Ave., STOP 8072. Pocatello, ID 83209, USA - delparte@isu.edu
}

Commission II

KEY WORDS: Coral Reefs, Coral Ecology, Habitat, Photogrammetry, Structure-from-Motion, Structural Complexity, 3D topographic reconstruction, 3D underwater modeling, Agisoft Photoscan, Pix 4D

\begin{abstract}
:
Structural complexity in ecosystems creates an assortment of microhabitat types and has been shown to support greater diversity and abundance of associated organisms. The 3D structure of an environment also directly affects important ecological parameters such as habitat provisioning and light availability and can therefore strongly influence ecosystem function. Coral reefs are architecturally complex 3D habitats, whose structure is intrinsically linked to the ecosystem biodiversity, productivity, and function. The field of coral ecology has, however, been primarily limited to using 2-dimensional (2D) planar survey techniques for studying the physical structure of reefs. This conventional approach fails to capture or quantify the intricate structural complexity of corals that influences habitat facilitation and biodiversity. A 3-dimensional (3D) approach can obtain accurate measurements of architectural complexity, topography, rugosity, volume, and other structural characteristics that affect biodiversity and abundance of reef organisms. Structurefrom-Motion (SfM) photogrammetry is an emerging computer vision technology that provides a simple and cost-effective method for $3 \mathrm{D}$ reconstruction of natural environments. SfM has been used in several studies to investigate the relationship between habitat complexity and ecological processes in coral reef ecosystems. This study compared two commercial SfM software packages, Agisoft Photoscan Pro and Pix4Dmapper Pro 3.1, in order to assess the cpaability and spatial accuracy of these programs for conducting 3D modeling of coral reef habitats at three spatial scales.
\end{abstract}

\section{INTRODUCTION}

The three-dimensional (3D) structural complexity of an ecosystem plays a key role in habitat provisioning and fundamental ecological processes. Habitat structural complexity creates an array of ecological niches and has been shown to support high levels of diversity and abundance of organisms (Crowder and Cooper 1982, Guinan et al. 2009, Graham and Nash 2013). Sessile reef-forming corals are primary contributors to the architectural complexity of coral reef ecosystems. The complex habitats created by corals support some of the most diverse, productive, and economically valuable ecosystems on the planet (Costanza et al. 1997, Moberg and Folke 1999, Hoegh-Guldber et al. 2007).

Increases in the frequency and intensity of both global (e.g., climate change, ocean acidification) and local (e.g., pollution, overfishing) stressors has led to significant coral mortality throughout the world's oceans (Harvell et al. 1999, Cesar et al. 2003, Hoegh-Guldberg et al. 2007, Burns et al. 2016). Multiple studies have found loss of live coral to cause reductions in reef complexity and detrimental impacts to associated reef fish and invertebrates (Graham et al. 2006, Alvarez-Filip et al. 2009, Walker et al. 2009, Graham and Nash 2013). The dynamic linkages between reef complexity and ecological processes are poorly understood as reefs have been conventionally assessed using two-dimensional (2D) metrics that are incapable of quantifying structural complexity (Alvarez-Filip et al. 2011, Graham and Nash 2013). Accurate measures of 3D reef structure are needed to determine how changes in coral cover and composition will alter large-scale processes and ecosystem services.
The influence of structural complexity on ecological function has been recognized for decades (Risk 1972, Luckhurst and Luckhurst 1978, MacArthur 1984, Kostylev et al. 2005), yet until recently the field of marine ecology has lacked methods capable of quantifying 3D features of reef environments. Structure-from-Motion (SfM) photogrammetry is an emerging photogrammetric technology that provides a cost-effective and automated method for creating high-resolution 3D reconstructions of natural environments. SfM photogrammetry can simultaneously determine both the camera positions and $3 \mathrm{D}$ geometry of a photographed scene by processing overlapping images collected with single-lens cameras (Snavely et al. 2008, Westoby et al. 2012, Fonstad et al. 2013). Eliminating the need for stereo cameras and known 3D camera positions drastically improves the ease and ability to generate high-resolution 3D models. Point clouds and digital surface models derived by SfM techniques have been shown to be comparable in terms of data quality and resolution to more expensive LiDAR techniques (Delparte et al. 2014, Javernick et al. 2014, Remondino et al. 2014). Several studies have utilized SfM techniques to create high-resolution 3D reconstructions of coral reef environments to investigate relationships between coral composition and habitat complexity (Burns et al. 2015, Figuera et al. 2015, Leon et al. 2015, Ferrari et al. 2016, Burns et al. 2016). Characterizing intricate $3 \mathrm{D}$ characteristics from coral reef environments can enhance the capability of researchers to investigate and monitor these valuable ecosystems.

The objective of this study was to compare 3D reconstructions of coral reef habitats created with the most commonly used commercial SfM software packages, Agisoft Photoscan Pro and 
Pix4Dmapper Pro 3.1. 3D reconstructions were created using the same sets of imagery at three spatial scales; individual coral colonies, $4 \times 4-\mathrm{m}$ reef plots $\left(16 \mathrm{~m}^{2}\right)$, and $10 \times 10-\mathrm{m}$ reef plots $\left(100 \mathrm{~m}^{2}\right)$. Three models were created for each spatial scale $(9$ total models). Image alignment, reprojection error, and spatial error of the resulting models were compared between the two software packages to examine differences in the capability of these programs for underwater modeling of coral reef environments.

\section{METHODS}

\subsection{Image acquisition}

Images were collected of coral reef environments at three spatial scales; individual coral colonies, $4 \times 4-\mathrm{m}$ reef plots, and 10x10-m reef plots (Figure 1). Ground control points (GCPs) and scale markers with known coordinates and dimensions were placed in each survey area to accurately georeference and ground-truth the resulting $3 \mathrm{D}$ reconstructions. Images were taken of the survey areas with $70-80 \%$ overlap from both planar and oblique angles. Images were taken with a Canon 5D Mark III digital SLR camera with a $24 \mathrm{~mm}$ lens in an Ikelite housing. Camera settings and image acquisition techniques used previously determined methods for investigating the 3D structure of coral reef ecosystems (Burns et al. 2015).

\subsection{D reconstructions}

3D reconstructions were rendered using Agisoft PhotoScan Pro and Pix4Dmapper Pro 3.1 software packages. The images from each survey were uploaded into both software programs and the SfM workflow was conducted in the following phases: 1) image alignment, 2) generation of sparse 3D point cloud, 3) GCP scaling and image optimization, 4) generation of dense 3D point cloud, 5) rendering of continuous mesh model, and 6) rendering of textured digital surface model. Digital markers were annotated onto the GCPs in each software package, and the known $x, y, z$ values for the GCPs were used to optimize image alignment and orientation of the resulting models.

\subsection{Assessment of 3D reconstruction and model accuracy}

The following metrics were extracted from each 3D model processed by both Agisoft Photoscan Pro and Pix4Dmapper Pro 3.1 software packages: 1) percentage of total images aligned, 2) reprojection error (pix), and 3) total spatial error (mm). The metrics were extracted by generating and exporting processing reports for each model. Percentage of aligned images indicates the amount of the images from the total image-set that could be aligned and incorporated into the resulting $3 \mathrm{D}$ reconstruction. The reprojection error is the geometric error corresponding to the euclidean image distance between a projected 3D point and the marked points based off the GCP locations. The differences between the marked and reprojected $3 \mathrm{D}$ points is the reprojection error, and the value is represented as pixels. Spatial error is based on the known spatial values of the GCP coordinates and scale bars compared to the computed values from the final 3D models.

\subsection{Statistical Analysis}

Mean values of the 3D reconstruction metrics were analyzed for each of the three spatial scales ( $n=3$ for each scale). The t-test function was used with the Welsh df modification for data with unequal variances. Mean values were compared for each metric to determine statistical differences between the two software

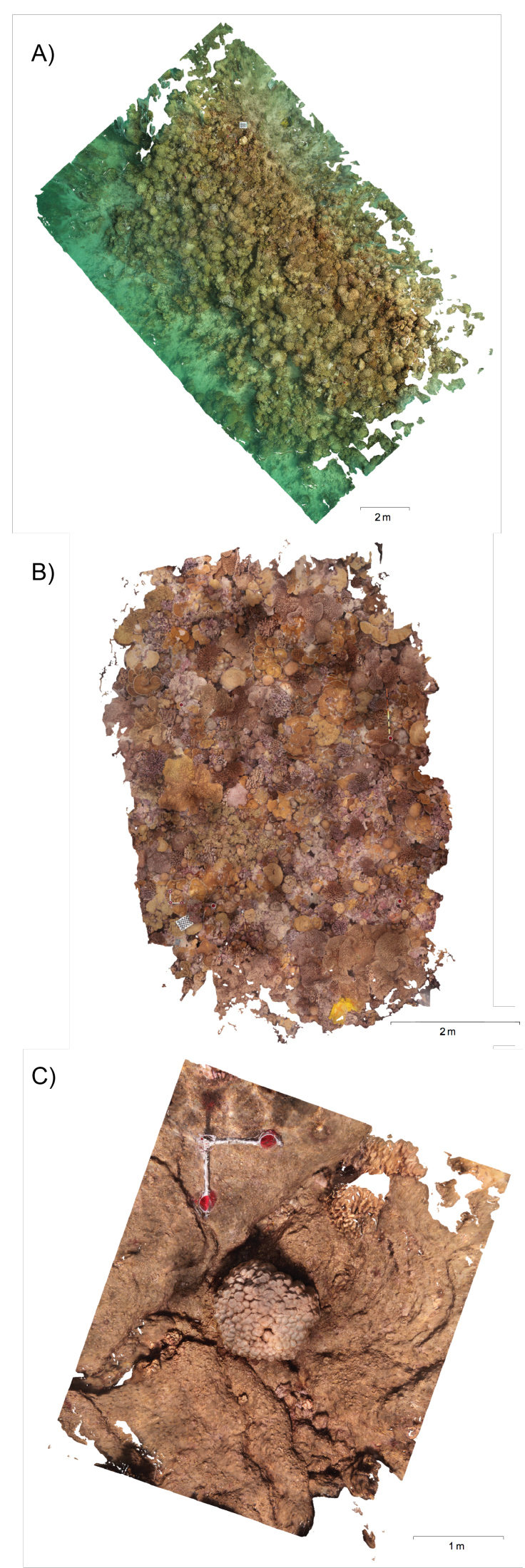

Figure 1. Photo-mosaics produced by the SfM 3D reconstruction process for the three spatial scales used in this study: a) 10x10-m $\left(100 \mathrm{~m}^{2}\right)$, b) $4 \times 4-\mathrm{m}\left(16 \mathrm{~m}^{2}\right)$, and c) individual coral colony. 
packages $(\alpha=0.05)$. All statistical tests were run using $R$ statistical software version 3.2.2.

\section{RESULTS}

Differences in the mean values of image alignment percentage were not statistically significant between the two software packages at the colony scale $(\mathrm{t}=-0.653, \mathrm{p}=0.56)$ or $4 \mathrm{x} 4-\mathrm{m}$ scale $(\mathrm{t}=1.689, \mathrm{p}=0.23)$. Mean values of image alignment percentage were significantly different between the two software packages at the $10 \times 10-\mathrm{m}$ scale $(\mathrm{t}=3.543, \mathrm{p}<0.05)$. Mean values of image alignment decreased with an increase in spatial scale for the Pix4D software package (Figure 1a).

Mean values of total spatial error $(\mathrm{mm})$ were significantly greater for 3D models created using the Agisoft software at the colony scale $(\mathrm{t}=8.845, \mathrm{p}<0.01)$. There was no significant difference in mean values of total spatial error $(\mathrm{mm})$ at the $4 \times 4$ $\mathrm{m}$ scale $(\mathrm{t}=1.706, \mathrm{p}=0.19)$ and $10 \times 10-\mathrm{m}$ scale $(\mathrm{t}=0.851, \mathrm{p}=$ 0.44 ) between the two software packages (Figure $2 b$ ).

Mean values of reprojection error (pix) were significantly greater for 3D models created using the Agisoft software at the colony scale $(\mathrm{t}=8.845, \mathrm{p}<0.01)$, the $4 \mathrm{x} 4-\mathrm{m}$ scale $(\mathrm{t}=11.924$, $\mathrm{t}$ $<0.01)$ and the $10 \mathrm{x} 10-\mathrm{m}$ scale $(\mathrm{t}=43.556, \mathrm{p}<0.01)$. Mean values of the Agisoft reprojection error (pix) were greatest at the $4 \times 4-m$ scale (Figure $2 \mathrm{c}$ ).

\section{CONCLUSIONS}

This study compared two commercial SfM software packages for creating underwater 3D reconstructions of coral reef environments. Metrics derived from the 3D reconstruction process were compared between Agisoft Photoscan Pro and Pix4Dmapper Pro 3.1 to assess the efficacy and spatial accuracy of these programs. Image alignment, total spatial error ( $\mathrm{mm})$, and reprojection error (pix) were used to investigate the ability of each software package to align underwater images and create spatially accurate 3D models that can be used for coral ecology studies. Comparisons were conducted at three spatial scales relevant to the field of coral ecology; 1) individual coral colony, 2) $4 \times 4-\mathrm{m}$ reef area, and 3) $10 \times 10-\mathrm{m}$ reef area (Figure 1). This is the first study to compare these commercial SfM software packages for generating 3D reconstructions of underwater environments.

No statistically significant difference was found in mean values of image alignment at the coral colony scale and $4 \times 4-\mathrm{m}$ scale, but Agisoft exhibited significantly higher values of image alignment at the 10x10-m scale (Figure 2a). The Agisoft software package consistently aligned more than $90 \%$ of the images for all three spatial scales while Pix4D exhibited a decrease in image alignment as the spatial scale increased. Since only three surveys were used for each spatial scale, a more robust dataset should be analyzed to determine if this trend is consistent among various types of habitat and continues at larger spatial scales. Previous studies have found variability between the image alignment and sparse point clouds generated by the two software packages in terrestrial systems (Georgopoulos et al. 2016), but no studies have tested differences between these SfM programs for underwater environments.

Total spatial error $(\mathrm{mm})$ was consistently higher in the 3D models produced with Agisoft software, but a statistically significant difference was only observed at the individual coral colony scale. Variability in the mean values of total spatial error was greater for both software packages as the spatial scale
A)

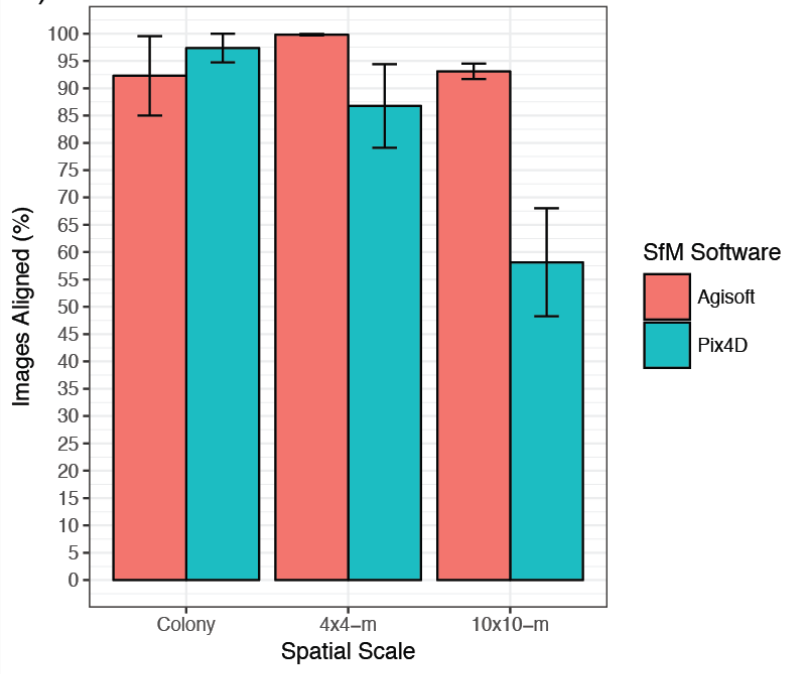

B)

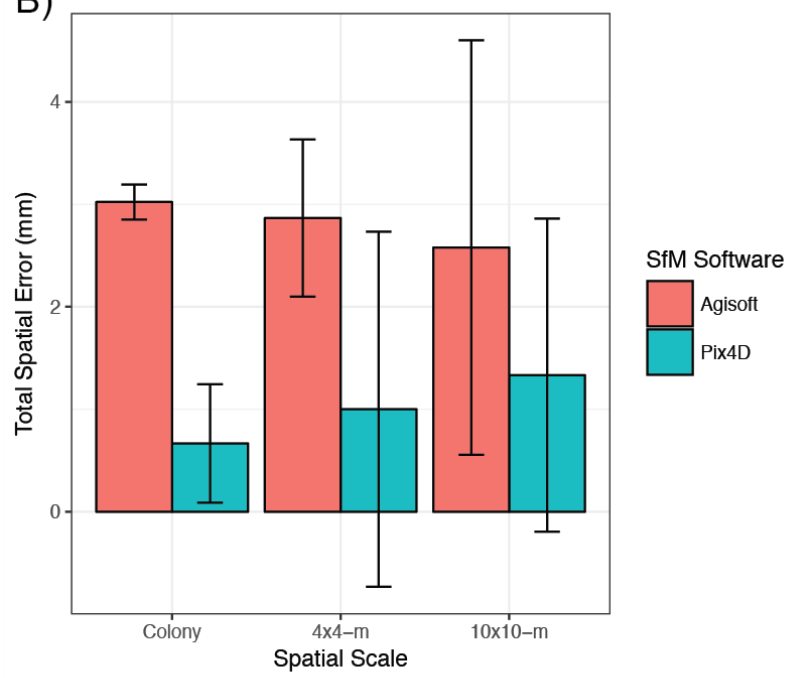

C)

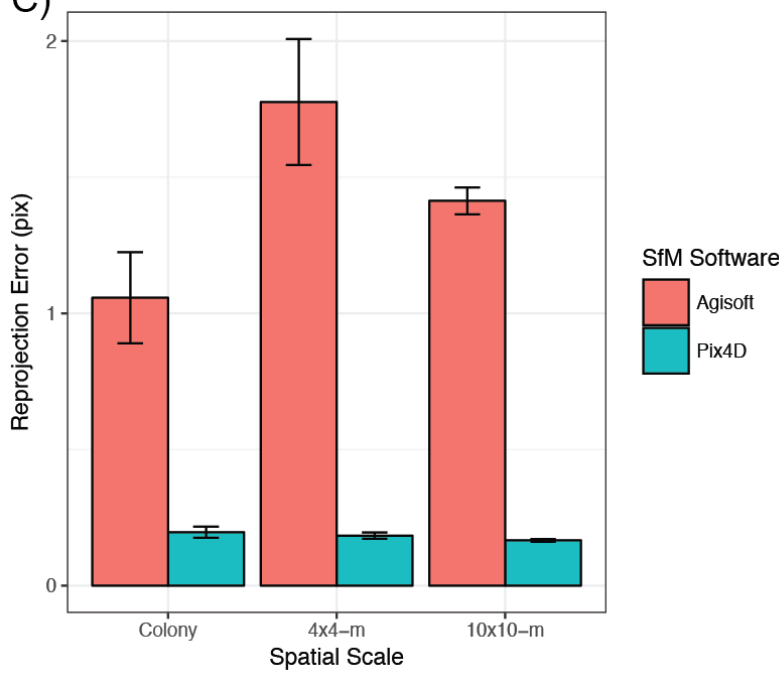

Figure 2. Statistical comparisons among mean values of 3D reconstruction metrics: a) image alignment, b) total spatial error $(\mathrm{mm})$, and c) reprojection error (pix). Error bars represent standard error of mean values for each parameter. 
increased, but all total spatial error was less than 5-mm (Figure $2 b$ ). While there were significant differences at the colony scale, both software packages produced high-resolution models with spatial accuracy of less than $1-\mathrm{cm}$. This finding highlights the capability of SfM 3D reconstruction techniques for quantifying detailed characteristics pertaining to habitat complexity in marine environments.

Mean values of reprojection error were significantly greater in all models processed using Agisoft software (Figure 2c). Reprojection error depends on the quality of the camera calibration (position and orientation), as well as on the quality of the marked GCPs on the images (position and zoom level at which the point is marked). This finding indicates Pix4D can perform high-quality internal camera calibration and exhibits very consistent reprojection error across several scales in marine environments. Both software packages had mean reprojection error values of less than 2-pixels across all spatial scales, which again indicates the effectiveness of these SfM programs for creating highly accurate $3 \mathrm{D}$ reconstructions of underwater habitats.

Previous studies have compared these specific software packages in terrestrial systems and found minor variability in 3D reconstruction capability between the two programs (Niederheiser et al. 2016). Our study found similar results using underwater images of coral reef environments at three spatial scales. Agisoft Photoscan Pro had a better capability of aligning images at larger spatial scales, and Pix4Dmapper Pro 3.1 exhibited higher spatial accuracy and lower reprojection error. Habitat complexity is known to be a key driver of ecosystem diversity and productivity (Goreau 1959, Knudby and LeDrew 2007, Walker et al. 2009, Dustan et al. 2013), yet until recently there have been few methods capable of quantifying intricate 3D characteristics of underwater environments. SfM techniques have been recently used in a range of applications to enhance the field of coral ecology and decipher how changes in reef structural complexity affect ecological processes (Burns et al. 2015, Figueira et al. 2015, Leon et al. 2015, Burns et al. 2016, Ferrari et al. 2016). This study further supports the use of SfM applications for the field of marine ecology, and shows that highly accurate 3D models can be reconstructed with both Agisoft and Pix4D software packages. As more studies use SfM techniques to for marine ecology applications, further investigations should be conducted to assess performance and accuracy among available SfM tools to guide researchers to obtain the best available software packages for their research approach.

\section{ACKNOWLEDGEMENTS}

This publication was developed under STAR Fellowship Assistance Agreement no. FP-91768001-0 awarded by the U.S. Environmental Protection Agency (EPA). It has not been formally reviewed by the EPA. The views expressed in this publication are solely those of the authors and EPA does not endorse any products or commercial services mentioned in this publication. We thank Raphael Ritson-Williams, Kristina Tietjen, Danielle Claar, and Lisa Szostek for assistance with fieldwork.

\section{REFERENCES}

Alvarez-Filip, L., Dulvy, N.K., Gill, J.A., Co^te', I.M., Watkinson, A.R., 2009 Flattening of Caribbean coral reefs: region-wide declines in architectural complexity. Proc R Soc Lond B Biol 276:3019-3025

Alvarez-Filip, L., N.K. Dulvy, I.M. Cote, A.R. Watkinson, and J.A. Gill., 2011. Coral identify underpins architectural complexity on Caribbean reefs. Ecological Applications 21(6):2223-2231

Burns, J.H.R., Delparte, D., Gates, R.D. and Takabayashi, M., 2015. Integrating structure-from-motion photogrammetry with geospatial software as a novel technique for quantifying $3 \mathrm{D}$ ecological characteristics of coral reefs. PeerJ, 3, p.e1077

Burns et al. (2016) Assessing the impact of acute disturbances on the structure and composition of a coral community using innovative 3D reconstruction techniques. Methods in Oceanography 15/16: 49-59

Cesar, H., Burke, L., and Pet-Soede, L., 2003. The economics of worldwide coral reef degradation. Technical Report

Costanza, R., R. d'Arge, R. de Groot, S. Farber, M. Grasso, B. Hannon, K. Limburg, S. Naeem, R.V. O’Neill, J. Paruelo, R.G. Raskin, P. Sutton, and M. van den Belt., 1997. The value of the world's ecosystem services and natural capital. Nature 387: 253260

Crowder, L.B., W.E. Cooper., 1982. Habitat structural complexity and the interaction between bluegills and their prey. Ecology 63:1802-1813

Delparte, D.M., M. Belt, C. Nishioka, N. Turner, R. Richardson, and T. Ericksen., 2014. Monitoring tropical alpine lake levels in a culturally sensitive environment utilizing 3D technological approaches. Arctic, Antarctic, and Alpine Research 46(4):709718

Dustan, P., O. Doherty, S. Pardede., 2013. Digital reef rugosity estimates coral reef habitat complexity. PLoS ONE 8(2):e57386

Ferrari, R., McKinnon, D., He, H., Smith, R.N., Corke, P., González-Rivero, M., Mumby, P.J. and Upcroft, B., 2016. Quantifying multiscale habitat structural complexity: a costeffective framework for underwater 3D modelling. Remote Sensing, 8(2), p.113

Figueira, W., Ferrari, R., Weatherby, E., Porter, A., Hawes, S. and Byrne, M., 2015. Accuracy and precision of habitat structural complexity metrics derived from underwater photogrammetry. Remote Sensing, 7(12), pp.16883-16900.

Fonstad, M.A., J.T. Dietrich, B.C. Courville, J.L. Jensen, and P.E. Carbonneau., 2013. Topographic structure from motion: a new development in photogrammetric measurement. Earth Surface Processes and Landforms DOI:10.1002/esp.3366

Goreau, T.F. 1959., The ecology of Jamaican coral reefs 1 . Species composition and zonation. Ecology 40:67-90

Graham, N.A.J., Wilson, S.K., Jennings, S., Polunin, N.V.C., Bijoux, J.P., Robinson, J., 2006. Dynamic fragility of oceanic coral reef ecosystems. Proc Natl Acad Sci USA 103:8425-8429

Graham, N.A.J., and K.L. Nash., 2013. The importance of structural complexity in coral reef ecosystems. Coral Reefs 32:315-326 
Georgopoulos, A., Oikonomou, C., Adamopoulos, E., \& Stathopoulou, E. K., 2016. Evaluating Unmanned Aerial Platforms for Cultural Heritage Large Scale Mapping. ISPRSInternational Archives of the Photogrammetry, Remote Sensing and Spatial Information Sciences, 355-362

Guinan, J., C. Brown, M.F.J. Dolan, and A.J. Grehan., 2009. Ecological niche modeling of the distribution of cold-water coral habitat using underwater remote sensing data. Ecological Informatics 4:83-92

Harvell, C.D., K. Kim, J.M. Burkholder, R.R. Colwell, P.R. Epstein, D.J. Grimes, E.E. Hofmann, E.K. Lipp, A.D. Osterhaus, R.M. Overstreet, J.W. Porter, G.W. Smith, and G.R. Vasta., 1999. Emerging Marine Diseases, Climate Links and Anthropogenic Factors. Science 285:1505-1510

Hoegh-Guldberg, O., P.J. Mumby, A.J. Hooten, R.S. Steneck, P. Greenfield, E. Gomez, C.D. Harvell, P.F. Sale, A.J. Edwards, K. Caldeira, N. Knowlton, C.M. Eakin, R. Iglesias-Prieto, N. Muthiga, R.H. Bradbury, A. Dubi, and M.E. Hatziolos., 2007. Coral Reefs Under Rapid Climate Change and Ocean Acidification. Science 318:1737-1742

Javernick, L., J. Brasington, and B. Caruso., 2014. Modeling the topography of shallow braided rivers using Structure-fromMotion photogrammetry. Geomorphology 213:166-182

Knudby, A., and E. LeDrew., 2007. Measuring structural complexity on coral reefs. In: Pollock NW, Godfrey JM, eds. Diving for Science 2007. Proc of the American Academy of Underwater Sciences $26^{\text {th }}$ Symposium pgs:181-188

Kostylev, V.E., J. Erlandsson, M.Y. Ming, and G.A. Williams., 2005. The relative importance of habitat complexity and surface area in assessing biodiversity: Fractal application on rocky shores. Ecological Complexity 2:272-286

Leon, J.X., Roelfsema, C.M., Saunders, M.I. and Phinn, S.R., 2015. Measuring coral reef terrain roughness using 'Structurefrom-Motion'close-range photogrammetry. Geomorphology, 242, pp.21-28

Luckhurst, B.E., and K. Luckhurst., 1978. Analysis of the influence of substrate variables on coral reef fish communities. Marine Biology 49:317-323

MacArthur, R. H., 1984. Geographical ecology, patterns in the distributions of species. Princeton University Press, Princeton, New Jersey, USA.

Moberg, F., Folke, C., 1999 Ecological goods and services of coral reef ecosystems. Ecological Economics 29:215-233

Niederheiser, R., Mokroš, M., Lange, J., Petschko, H., Prasicek, G., \& Elberink, S. O., 2016. Deriving 3d Point Clouds from Terrestrial Photographs-Comparison of Different Sensors and Software. International Archives of the Photogrammetry, Remote Sensing and Spatial Information Sciences-ISPRS Archives, 41, 685-692.

Remondino, F., Spera, M.G., Nocerino, E., Menna, F., Nex, F., 2014. State of the art in high density image matching. In: The Photogrammetric Record 29, pp. 144-166. doi:10.1111/ phor.12063
Risk, M.J., 1972. Fish diversity on a coral reef in the Virgin Islands. Atoll Research Bulletin 153

Snavely, N., S.N. Seitz, and R. Szeliski., 2008. Modeling the world from internet photo collections. International Journal of Computer Vision 80:189-210

Walker, B.K., L.K.B Jordan, and R.E. Spieler., 2009. Relationship of reef fish assemblages and topographic complexity on Southeastern Florida Coral Reef Habitats. Journal of Coastal Research 25(6):39-48

Westoby, M.J., J. Brasington, N.F. Glasser, M.J. Hambrey, and J.M. Reynolds., 2012. 'Structure-from-Motion' photogrammetry: A low-cost, effective tool for geoscience applications. Geomorphology 179:300-314 